\title{
Discussion on the Fashion of Literati and Officialdoms Painted in "Listening to the Qin" in Song Dynasty
}

\author{
Yida $\mathrm{Wu}^{1, *}$ \\ ${ }^{1}$ Academy of Seal Cutting, Chinese National Academy of Arts, Beijing, China \\ *Corresponding author. Email: zongwubj123@qq.com
}

\begin{abstract}
In Emperor Huizong of Song Dynasty's "Listening to the Qin", the player is dressed in Taoist clothes, reflecting a style of clothing of the Northern Song Dynasty literati and officialdom class. Fan Zhongyan in the Northern Song Dynasty recorded the fashion of Taoist literati and officialdoms wearing Taoist clothing in words, while Su Shi in the Northern Song Dynasty recalled the scene of Zhang Xian wearing fur cloak with crane pattern in the form of poetry. Therefore, from the mutual confirmation of images and documents in the Northern Song Dynasty, people can see the clothing fashion pioneered by scholars and doctors in the Song Dynasty.
\end{abstract}

Keywords: "Listening to the Qin", Taoist clothing, Fur cloak with crane pattern, Clothing fashion.

“东坡中，中有四墙，墙外有重墙，比内墙少杀。前后左右以角相向，著之则有界角在两眉间，以老坡所服，故名。尝见 其画像, 至今冠服犹尔。”

(Dongpo kerchieves have double layers and four sides, and the corners between the eyebrows are more square-folded. Because Su Dongpo often wears this style of kerchief, it is called Dongpo kerchief. I have seen Dongpo's portrait before, and now there are people wearing Taoist clothes and Dongpo kerchief.)

\section{INTRODUCTION}

According to the sayings, "Listening to the Qin" is a meticulous figure painting in ink and color on silk created by Song Huizong. It is $147.2 \mathrm{~cm}$ in length and $51.3 \mathrm{~cm}$ in width. It is now in the Beijing Palace Museum. In the middle of the picture, there is a Qin player, dressed as a Taoist priest, and there is a wooden table beside it, on which is placed an incense burner, and a wisp of incense smoke is slowly rising. The player lowered his head and flicked the strings with his hands. Behind it is an old pine tree, which is like a dragon. The midnight flower is clinging to it, and red and white flowers are dotted with it. On the right side of the tree, a few green bamboos are gathered and scattered, and they are verdant and lovely. There were three people who listened to the Qin, and two of them were wearing court dresses and hats, sitting opposite each other, listening attentively. On the left hand of the player, there is a person with a gauze hat and red robe, holding a fan on the knees in one hand, supporting on a stone pier with the other hand, sitting down on the side, seeming to be intoxicated by the sound of the Qin; On the right hand of the player, there is a person in a green robe with a gauze cap and his hands are held in his sleeves. He leans up and lean forward slightly, seeming to be moved by the sound of the Qin; a boy standing beside him seems to be attracted by the sound of the Qin. In the foreground of the picture, there is also an exquisite ornamental stone with an ancient tripod on which a bunch of flower branches are inserted.

The composition of this work is simple and clean, the color is calm and elegant, the characters are vividly portrayed, the lines of the clothes are very detailed, the blending changes are suitable, the beard lines are thin and powerful, and the blending layers are distinct. The depiction of the tree and stone utensils is precise but not dull, and the soft and hard textures of the tree and stone and the cushion are in sharp contrast. They are typical works of the Song Dynasty Xuanhe Painting Academy painters depicting the life in the Palace of 
Emperor Huizong of Song Dynasty. On the left side of the picture, there is the inscribed "天下一人(tiān xià yī rén, means the emperor of this country)" by Emperor Huizong of Song Dynasty, and a seal of characters on a seal carved in relief "御书 (yù shū, means book of the emperor)". On the top of the screen, there is a seven-character quatrain inscribed by Cai Jing of the Northern Song Dynasty: "吟徵调 商灶下桐, 松间疑有入松风。仰窥低审含情客, 似听无弦一 弄中。 (The paulownia wood cooked under the stove next door is a good material for making guqin. There seems to be the sound of the guqin song "Wind into the Pine" in the pine room. Looking down at the people watching and listening to the Qin in secret, it seems that everyone is connected.)" The inscription is "臣京谨题 (sincerely inscripted by Cai Jing)", and there are three words "听琴图 (Picture of listening to the Qin)" in the upper right corner of the slender gold.

\section{2. "TAOIST CLOTHES" IN "LISTENING TO THE QIN"}

The shape and structure of Taoist clothes are diagonal collars and gussets, taking black cloth to cover all the edges of the clothing, or it is also called as Taoist robe when using dark brown on the clothes. When wearing the Taoist clothes, silk ribbons are sometimes used to restrain the waist. The central figure in the picture of "Listening to the Qin" is not only dressed in "Taoist clothes", but also dressed as a "Yellow crown Taoist". This extends an important question, why do literati scholars wear Taoist clothes? Generally speaking, Taoist clothes are the clothes worn by Taoist priests, but it is interesting for literati and officialdoms to wear Taoist clothes. People may be able to find some clues in the "Praise of Taoist Clothes" written by Fan Zhongyan in the Northern Song Dynasty. Comparing the image depiction of Taoist clothes in "Listening to the Qin" with the written records in "Praise of Taoist Clothes", people can see two specific expressions and expressions, one is the image depiction of the Taoist clothes worn, and the other is the written record of the Taoist clothes.

There are many kinds of common Taoist costumes. What is depicted in "Listening to the Qin" is one of the forms of Taoist clothes, that is, "Taoist robes". Taoist robes are generally made of white, gray, and brown cloth soap. From the image, it can be seen that the high-quality Taoist cloth depicted in "Listening to the Qin" is a high-quality Taoist robe. This robe has a large bosom and wide sleeves, down to the knee, with black borders on the collar, sleeves, placket and hem, black borders around the hem, and horizontal gussets on the waist. In the Sui and Tang dynasties, the literati and officialdoms wore ordinary clothes which were generally called "襕衫 (lán shān, means robe or shirt)", that is, adding a robe or shirt under the round neck. "New Book of Tang: Records of Vehicles and Clothes" records "the scholar's uniform is the short brown, and the common people are in white. Head of the secretariat Ma Zhou carried out a discussion in the court: there is no content about clothes in the rite, and there are dark color clothes in the system of three generations. Please add robe, sleeve, tapeon, and edge ornaments on the scholars' up-shirts. The one with a crack on the hip called quekua shirt. The robe is a longer tunic, not like the short tunic on the inside, but only a horizontal tunic is added under it. This is similar to the tunic robe. In daily life, scholars generally wear a scarf or a sacred head" [1]. During the Five Dynasties, literati and officialdoms used the old uniforms of the Sui and Tang dynasties. The most intuitive image is the "Han Xizai Night Banquet" painted by Zhou Wenju of the Five Dynasties. Although Han Xizai was a court official in identity, he still belonged to a scholar in essence. Looking at the uniforms and fashions of the scholars during the Five Dynasties, Han Xizai wears a gauze hat in the "Han Xizai Night Banquet" and during the period of the Five Dynasties and Ten Kingdoms, the clothing generally followed the Tang system.

The Taoist clothing in "Listening to the Qin" is the "襕衫 (a kind of robe)" of the Song Dynasty. This kind of "robe" is described in "Song History and Records of Clothes" as: "the robe is made of white fine cloth, with round neck and large sleeves. There is a belt and the cloth under the belt called skirt. There are pleats on the waist. Jinshi (the successful candidates in the highest imperial examinations), students of imperial classes, and students of county wear this kind of robe". According to Zhou Xibao's "History of Ancient Chinese Costumes", the Taoist costumes include zhiduo (a kind of a robe), Taoist clothes (Taoist robe), and fur cloak with crane pattern. They were all worn outside by the literati and officialdom class in the Song Dynasty, and they were relatively wide and large. The figures in "Listening to the Qin", the Taoist clothes worn outside the dresses, may be a shorter Taoist clothes such as a fur cloak with crane patternd, and the small crowns they wear are also Taoist clothes. 
"Crown" is a special headdress on the head of aristocratic men in ancient times. It is one of the important signs of the nobleman's clothing. Its main practical function is neither protection nor warmth. In terms of use, when people wear a crown, they should use the hairpin to traverse the middle of the hair. The crown is tasseled and hangs between the submandibular neck and the neck. For the small crown, only hairpins are used without tassels, and Hengqi (hairpins) run across the bun for stability. In "Listening to the Qin", the person who touches the piano wears a small crown, and there are no tassels and it is tied between the submandibular neck and the neck. This kind of costume culture with small crowns is still in the aesthetic culture of Taoist costumes.

\section{3. "TAOIST CLOTHES" IN "PRAISE OF TAOIST CLOTHES"}

"Praise of Taoist Clothes" is written in lower case, one volume on paper, $34.8 \mathrm{~cm}$ in length and $47.9 \mathrm{~cm}$ in width, and is now in the collection of the Palace Museum in Beijing. The description of Taoist clothes in the written text of Praise of "Taoist Clothes" is: "Praise of Taoist Clothes (a style) and preface (preface)": Xu Pinghai (person's name) made Taoist clothes (a kind of clothing), the purpose is to put on Taoist clothing to refresh one's will and cleans the body. Xu Pinghai asked classmate Fan Zhongyan to write a compliment. The article said: "Taoists wear neat and beautiful clothes. When a gentleman puts on (Taoist clothes), it will relax his spirit and make his heart clean and clear. Don't you have noble cyan purple clothes? It's just that you know that arrogance is the source of humiliation. Don't you have a fur coat made of fox and raccoon fur? It's just that you know that arrogance is the source of humiliation. You value this uniform as if you respect the teacher, and fear the official uniform as if you are afraid of a tiger. You are the descendant of Xu Xun, the immortal of Jingyang, and your Taoism is worthy of your ancestor $\mathrm{Xu}$ Zhenjun."[2]

From the Northern Song Dynasty Fan Zhongyan's "TPraise of Taoist Clothes", peop can see several aspects of information. First, in the Song Dynasty, the three schools of Confucianism, Buddhism, and Taoism have merged into one by the literati and officialdom class in Song Dynasty. The Su Shi phenomenon appeared in the Song Dynasty literary and art circles. Second, Fan Zhongyan said thoroughly in the "Praise of Taoist Clothes", because Brother Xu (Dao Xi) made the
Taoist clothes to show his purity and cleanliness, that's why Fan Zhongyan wrote this compliment.

It can be seen that Tao clothes was very popular in the Northern Song Dynasty. Not only the bureaucrats of the literati and officialdom class liked it, but even the people depicted in "Listening to the Qin" also liked Tao clothes. Wearing Taoist clothes in the Song Dynasty was like entering the world with the Confucian spirit as reflected in Fan Zhongyan's "Praise of Taoist Clothes", treating his fame and reputation as a Taoist person. This kind of spirit is just a satire of people like "people who are unclean and self-defeating". The volume of Su Shi's calligraphy, Zhiping Tie, now in the Palace Museum in Beijing, depicts Su Shi wearing a Taoist dress, wearing an Dongpo scarf and a hood, standing with his hands in an arched position, wide robe with large sleeves, and a circle of colors on the cuffs, neckline and bottom of the robe. He is wearing a wide robe with large sleeves, and the cuffs, neckline and bottom of the robe are decorated with a wide band of heavier colors, which is in the same line as the style of the Taoist clothes of the Qin player in "Listening to the Qin".

\section{SONG PEOPLE'S BUN FASHION}

In "Listening to the Qin", the Qin player not only wears a Taoist costume, but also wears a small crown as a Taoist costume. "'Tao robe' is a robe often worn by Taoists and monks. It is made of white, gray, and brown coarse cloth, with large placket and wide sleeves, down to the knee, with black edges on the collar, sleeves, placket, and gusset" [3]. In addition, "the hair is tied with a crown, its crown has names such as 'yellow crown', 'golden crown', 'furong crown', 'five-mountain spiritual figure crown', and 'two ritual crown', etc." [4]. Taking a closer look at the clothes of the player in the painting "Listen to the Qin", it is similar to the Taoist costumes in the Song, Liao, Jin and Yuan periods described in the fifth chapter of "The History of Chinese Apparel Aesthetics". It's just that the player in the picture scroll of "Listen to the Qin" is not made of coarse cloth, but made of more advanced silk fabrics such as silk fabrics. This style of clothing was used as daily clothing by future generations of scholars.

Judging from the hair decoration of those wearing Taoist clothes, the towels worn by Taoists in the Song Dynasty included "chunyang kerchief", "ziyang kerchief", "fu kerchief" and "hunyuan kerchief". " 巾 jīn" was originally a kerchief wrapped around the head. In ancient times, the head 
was wrapped with a ruler cloth as a scarf. Later generations stitched the kerchieves with gauze, and the square one was a scarf. In the Song Dynasty, the roof of kerchieves (the kerchieves had a rooflike shape) became more and more towering, and the texture was also made of silk gauze in addition to the original cloth gauze. In terms of form, the "Dongpo kerchief" appeared in the style of the headscarf worn by the celebrity Su Shi.

In addition, the Song Dynasty handed down "The Portrait of Su Changgong" can more directly reflect the clothing that Song Dynasty scholars like to wear. In this picture, Su Shi wears a high barrel hat, a large sleeve robe, a straight collar, and a fur cloak with crane pattern. The clothing style is the same as the fur cloak with crane pattern worn by the player in "Listening to the Qin", except that the texture of the fabric is different. The literature records that $\mathrm{Su}$ Shi's "Seeing Zhang Ziye and Writing Him Three Quatrains: Memories in the Bamboo Pavilion" of the Song Dynasty says: "The bamboo on the south bank of Baitang is like a cloud (雲 cloud), who is the owner of this pavilion. So I made Ziye put on a fur cloak with crane pattern, he doesn't need to be more happy and innocent" [6]. This shows that $\mathrm{Su}$ Shi recalled Zhang Ziye wearing a fur cloak with crane pattern.

\section{CONCLUSION}

To sum up, the reason why the literati scholars in the Song Dynasty created Taoist clothes and became a fashion. It is believed that: First of all, as Fan Zhongyan said, through wearing the Taoist clothes, it is reflected that scholars of literati enter the world with the Confucian spirit and treat their fame and reputation as clear and clean as those of Taoism, and this spirit is an irony to people like those who are "unclean and self-defeating". Second, it shows profound socio-political reasons. As it known to all, the Song Dynasty implemented the policy of advocating literature and suppressing military affairs. The rulers raised the status of civil servants, widely absorbed high-quality literati scholars into the dynasty as officials, and provided superior treatment for literati and official officials. As a result, the number of scholars who aspire to pass the imperial examinations to become official officials has increased, and the number of scholars has been increased, making it possible to wear Taoist clothes as a fashion. Third, the literati and Confucian scholars in the Song dynasty's sentiments for helping the world, with the courage to speak directly, became the prevailing style of the era, forming a zeitgeist and social customs, and the general respect and respect of scholars from the ruling and opposition parties to the scholars of the world. This is a profound social and ethical reason why scholars of Song Dynasty wore Taoist clothes Fourth, the most outstanding representatives of scholars in the Song Dynasty, such as Su Dongpo, Fan Zhongyan, and others in literary and artistic creation and their ability to save the world, also their "excellent and elegant" talents and beauty, became the social yardstick for advocating elegance and admiring talent in the Song Dynasty. The clothing handed down by $\mathrm{Su}$ Dongpo, Fan Zhongyan and other literati who possessed "extraordinary talents" with both the beauty and the worldly sentiment will naturally become the social clothing fashion of the time. Coupled with the pure and clean cultural elegance of Taoist clothes in the minds of literati, Taoist clothes were fixed by this popular fashion clothing and followed the Yuan and Ming Dynasties. During the Yuan and Ming Dynasties, the Taoist clothes worn by literati and officialdoms had no major changes in style, only the texture of the fabric, and the Taoist clothes made of silk and satin appeared.

\section{AUTHORS' CONTRIBUTIONS} $\mathrm{Wu}$.

This paper is independently completed by Yida

\section{REFERENCES}

[1] (Song Dynasty) Ouyang Xiu, New Book of Tang [M]. Jilin People's Publishing House, 1995, p288. (in Chinese)

[2] Yang Jingru, Chronicles of Suzhou Prefecture [M]. Soochow University Press, 2013, p151. (in Chinese)

[3] Cai Zi'e, History Of The Aesthetics Of Chinese Dress [M]. Hebei Fine Arts Publishing House, 2001, p660. (in Chinese)

[4] Cai Zi'e, History Of The Aesthetics Of Chinese Dress [M]. Hebei Fine Arts Publishing House, 2001, p660. (in Chinese)

[5] Cai Zi'e, History Of The Aesthetics Of Chinese Dress [M]. Hebei Fine Arts Publishing House, 2001, p670. (in Chinese)

[6] (Song Dynasty) Su Shi, copyright, Li Zhiliang, noted, Annotation to Su Shi's Anthology [M]. BaShu Press, 2011, p120. (in Chinese) 